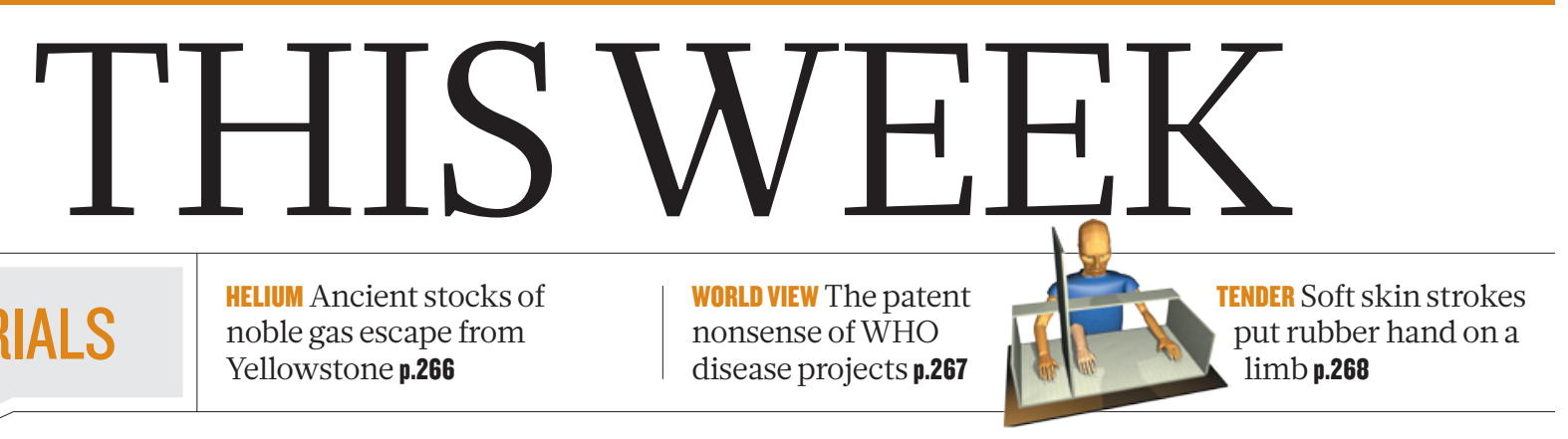

\title{
Not so neutral
}

\section{Switzerland's science landscape is under threat after a narrow majority of citizens voted for tighter immigration rules that could restrict the number of foreign scientists who work in the country.}

I ts great desire for independence notwithstanding, Switzerland is superbly integrated into the global pursuit of scientific research. The small Alpine country maintains some of Europe's strongest research universities and hosts one of the world's most outstanding research facilities, CERN - Europe's particle-physics laboratory near Geneva. The nation has also taken on a lead role, financially and logistically, in the Human Brain Project, a $€ 1$-billion (US\$1.4-billion) collaboration to simulate the human brain in a supercomputer.

The outcome of an ill-conceived referendum on 9 February against 'mass immigration' threatens to spoil Switzerland's beautiful science landscape (see page 277). The motion was approved by a narrow majority despite opposition from the government, parliament and Swiss lobby groups, including those from science and industry.

The government now has three years to implement tighter immigration rules that could restrict how many foreign scientists can be employed at the country's universities and research institutes. The European Union (EU) has already shown that it is not going to relax its fundamental principles in deference to Swiss xenophobia. Last weekend, Switzerland - an EU associate member — refused to sign an agreement that would extend the right to free movement within the EU to the bloc's newest member, Croatia. The European Commission immediately suspended talks over Switzerland's association in the EU's $€ 80$-billion Horizon 2020 research programme. Clearly, the nation's U-turn will not be without consequences.

Switzerland prides itself on a tradition that grants its citizens more far-reaching rights of co-determination than any other democracy. Its relatively small geographical size and population, high level of literacy and well-developed pragmatism all seem to favour that special form of government.

But direct democracy becomes problematic if it is driven by populism and irrational fears, such as those over unemployment and crime (Switzerland is, in fact, one of the safest countries in the world, and the current unemployment rate is barely 3.5\%). Certainly, immigration there has increased over the past decade - but this is in large part because the economy and health system rely heavily on the services of foreign workers. Ironically, the initiative to 'stop mass immigration' got the highest level of support in rural areas, where there are relatively few foreigners. In cosmopolitan cities, such as Zurich, Basle and Geneva, a majority of voters rejected the initiative.

This is not the first time that an initiative by the Swiss people has clashed with the interests of science. In 1992, they voted to include the protection of the dignity of animals in the constitution, which made animal experiments much harder for scientists to justify. In 1998, an initiative aimed at banning the use of transgenic animals failed narrowly — after scientists lobbied vociferously against it.

Fortunately, the wording of the latest initiative offers enough leeway for the Swiss government to avert unintended harm to science. For example, the government is free to include provisions that would

exempt foreign scientists - and possibly other groups of professionals, such as nurses - from the restrictions altogether. It needs to do so. Alternatively, it might assign future immigration quotas regionally, so that rural cantons could restrict immigration more than the urban regions that host universities and research institutes, and which voted against the measure.

The European Commission should stand firm on its decision to halt Horizon 2020 talks. It is unfortunate that science will be a casualty

"Switzerland cannot play fast and loose with international agreements on free movement." of a broader political fight but, in this case, principles matter. Switzerland cannot play fast and loose with international agreements such as those on the free movement of Europeans. If the country is to remain at the forefront of prestigious international research collaborations such as the Human Brain Project, it must make assurances that scientists can continue to participate on Swiss soil, and find a way to make it happen.

Switzerland's regrettable course is a setback to Brussels' vision of a pan-European Research Area where scientists, knowledge and ideas can move freely across borders. Indeed, it is a setback to any attempt to fight the populist rhetoric that immigration is a threat.

As the drama plays out between Bern and Brussels, European scientists and science organizations should seek to maintain, and where possible enhance, mutual collaboration with this exceptionally science-minded nation. But in this centenary year of the outbreak of the First World War - modern Europe's original sin — Switzerland must be reminded that nationalism and exclusion are anachronisms of the worst kind.

\section{Intelligent testing}

Science has a part to play in ensuring protection for defendants with intellectual disabilities.

$\mathrm{M}$ ost societies recognize that it would be wrong to execute someone like Lennie Small, the mentally disabled character in John Steinbeck's 1937 novella Of Mice and Men, even though he murdered a woman while stroking her soft hair.

Lennie never understood what he did wrong, and that ignorance usually brings protection from the full force of the law. Most countries with a death penalty have some sort of special treatment for the mentally disabled enshrined in the judicial system.

Few intellectually disabled people are as obviously impaired as Lennie, so expert assessments - and science - are usually used to 
decide their fate. Most US states, for instance, use an IQ test to assess cognitive skills such as problem-solving and anticipating the consequences of actions. Lennie would have scored low: when the woman screamed, his reasoning power was so limited that he could come up with no other option but to kill her. The tests can provide an accurate measure of some cognitive skills and, better yet, seem to offer an objective metric for prosecutors to work with. No test of cognitive ability, however, can determine a person's understanding of guilt, and thus their culpability for a crime. That problem becomes especially difficult when defendants have a mild intellectual disability.

Faced with such cases, some court systems use IQ score as a proxy to assess the deeper issue of awareness. Florida is one, and early next month its controversial approach will be tested. As we report on page 284, on 3 March the US Supreme Court will begin hearing arguments on behalf of Freddie Lee Hall, a convicted murderer. Hall has a low IQ, but not consistently low enough (below 70) to escape the death penalty in Florida. He and his lawyers want the state to raise its IQ cut-off point.

The state has refused. A weakening of its criteria, officials say, could prompt hundreds of appeals. One estimate suggests that in the United States, up to $20 \%$ of the 3,100 or so people on death row may have some level of intellectual disability (R. Coyne and L. Entzeroth Geo. J. Fighting Pov. 3, 40; 1996). And if it relaxes its strict interpretation, the state worries, could not a clever lawyer or sympathetic psychiatrist claim that a client facing the death penalty has a mental disability due to post-traumatic stress disorder, temporary insanity or a bout of depression? Defendants, lawyers and officials in other states are watching with interest.

If the United States is to have a death penalty - and 55\% of Americans supported it in a 2013 survey - it should ensure that all defendants have an equal, objective chance to save their own lives. Many states try to ensure this by drawing a 'bright line' at an IQ score of 70 . But this greatly overestimates the IQ test's precision. The tests have a ten-point margin of error - they cannot necessarily distinguish a 71 from a 69. If IQ tests were to be scrapped as a way to judge criminal competence, what could replace them?

In its latest version of the Diagnostic and Statistical Manual of Mental Disorders (DSM-5), the American Psychiatric Association changed both the definition and the name of intellectual disability, formerly known as mental retardation. It now avoids setting any IQ limit for the disorder, and emphasizes the impact of cognitive ability on behaviour.

Related to this approach is the adaptive behaviour test. Designed to measure how well a person can manage in the real world by quizzing

"Too little is

known about how intelligence plays into criminality." his or her family and acquaintances, when administered by experts, this standardized test gives the kind of consistent, numerical results that prosecutors crave.

Psychologists in the United States are already designing a modified version called the Diagnostic Adaptive Behavior Scale, the first evidence-based, adaptive behaviour test designed specifically for young people with a low IQ. Relevant to the debate over mental dysfunction and the death penalty, it assesses traits such as gullibility and the ability to solve social problems. Properly administered, it could determine awareness for courts better than existing tests of IQ.

Too little is known about how intelligence plays into criminality and the various environmental factors that affect it (such as decades spent in prison). If science is to provide courts with more certainty about the state of mind of defendants, then more research is needed on the nature of intelligence itself.

For example, Kent Kiehl, a psychologist at the University of New Mexico in Albuquerque, is compiling 3,000 brain scans of prisoners in what is already the largest collection of images of criminal minds in the world. Kiehl's main aim is to assess factors such as psychopathy, or whatever it is that makes people commit crimes, but he also wants to develop a test to predict intelligence. Adding this to the arsenal of such tests could help to assuage prosecutors' concerns about a defendant faking disability, or an expert giving a biased diagnosis.

In Steinbeck's book, Lennie pays the ultimate price for both his crime and his disability. Justice demands that we separate the two. Science will keep trying to do so.

\section{Helium high}

\section{Many bemoan the shortage of helium for the lab, but for geologists, its true value is in the ground.}

\section{$\mathrm{T}$} The ancient mariner and his ill-fated shipmates in Samuel Taylor Coleridge's epic poem were tormented by the sight of "Water, water, every where/Nor any drop to drink". That sentiment is likely to be shared by physicists and other researchers who have struggled in recent years to find cheap helium for their studies, equipment and experiments, when they read that massive quantities of the gas have been found escaping from the well-trodden and turbulent ground of Yellowstone National Park in Wyoming.

And we do mean massive amounts. Perhaps one billion years' worth of stored helium is fizzing up from Earth's crust beneath Yellowstone, only to disappear into thin air.

Meanwhile, the US Geological Survey (USGS) reported last month that helium prices reached an 18-year high in the 12 months to September 2013 - around the same time that the US Congress voted to postpone closure of the nation's strategic helium reserve. In doing so, Congress overruled an older law requiring that the United States sell off supplies of the gas that it has hoarded since the 1920s - an economic albatross around the neck of the laws of supply and demand that many blame for the current price volatility (see Nature http://doi.org/rkc; 2013).
The United States is by some distance the world's largest helium supplier. Yet there is unlikely to be a sensible and affordable way to tap the gas flooding into the atmosphere at Yellowstone. So, the waste is inevitable. Instead of bemoaning it, admire the science it brings. As useful as extracted, processed and packaged helium is to researchers in the lab, the true value of this noble gas for Earth scientists lies in the ground. Subterranean helium is a crucial geophysical tracer and one used, for example, to date groundwater and to track the rise of the continents.

Around the world, geysers and hot springs bubble this telltale helium to the surface. The ratios of helium isotopes in such escapes provide clues about the characteristics of volcanic activity in the crust and mantle. At Yellowstone, these isotopes help geologists to make sense of a particular super-volcano feature called the Yellowstone hotspot.

Much of the helium emitted at Yellowstone is helium-4, an isotope produced by radioactive decay of elements such as uranium and thorium in the crust. (The other common isotope, helium-3, is a primordial relic of the formation of the planet.)

On page 355 of this issue, Jacob Lowenstern and his colleagues at the USGS show that the helium- 4 emission rates from Yellowstone exceed any conceivable rate of generation within the crust. Instead, it must have accumulated in the crust underneath Yellowstone for hundreds of millions of years, until the geological carnage of the Yellowstone $\rightarrow$ NATURE.COM To comment online, click on Editorials at: go.nature.com/xhunqu hotspot allowed it to escape. Perhaps one billion years' worth has been liberated over the past two million years. And still it comes. As Coleridge said, "The very deep did rot: O Christ!/That ever this should be!" 